\title{
DINÂMICA DO USO DA TERRA NA ÁREA DO PARQUE NACIONAL DE ITABAIANA ANTES E DEPOIS DA CRIAÇÃO DA RESERVA
}

\author{
Iasmin Teles Carvalho ${ }^{(\mathrm{a})}$; Bartira Alves de Melo $^{(\mathrm{b})}$, Daniel Rodrigues de Lira ${ }^{(\mathrm{c})}$, Cristiano \\ Aprígio dos Santos ${ }^{(\mathrm{d})}$ \\ (a) Departamento de Geografia Itabaiana - DGEI, Universidade Federal de Sergipe - UFS, E-mail: \\ iasminteles97@gmail.com \\ (b) Departamento de Geografia Itabaiana - DGEI, Universidade Federal de Sergipe - UFS, E-mail: \\ bartiramelo1997@hotmail.com \\ (c) Departamento de Geografia Itabaiana - DGEI, Universidade Federal de Sergipe - UFS, E-mail: \\ aprigeo@gmail.com \\ (d) Departamento de Geografia Itabaiana - DGEI, Universidade Federal de Sergipe - UFS, E-mail: \\ dniellira@gmail.com
}

\section{Eixo: GEOTECNOLOGIA E MODELAGEM ESPACIAL EM GEOGRAFIA FÍSICA}

Resumo

O Uso da terra pode ser considerado a forma na qual o espaço está sendo ocupado o que ocasiona grandes impactos, geralmente onde não há planejamento adequado, ocorre degradação exacerbada da terra e de seus recursos naturais. A relação entre sociedade e natureza tem acarretado impactos ambientais, devido à necessidade de uma maior exploração dos recursos, é o caso do Parque Nacional da Serra de Itabaiana. Para melhor entender essa dinâmica utilizou-se imagens de satélite de antes e posterior a criação do parque sendo. A partir da elaboração dos índices e posterior fatiamento e classificação, a imagem correspondente apenas a área do Parque chegou-se ao seguinte resultado: Pastagem, Vegetação Esparsa, Vegetação Densa. Foi possível constatar que após a criação do parque as áreas de vegetação densa cresceram e as áreas de pastagem reduziram de tamanho.

Palavras: SIG, Índice de Vegetação, Ação Antrópica

\section{INTRODUÇ̃̃̃O}

O Uso da terra pode ser considerado a forma na qual o espaço está sendo ocupado o que ocasiona grandes impactos aos recursos naturais, quando não organizado e feito de forma racional. De acordo com Mendonça (1997), a identificação da ocupação dos tipos de uso da terra constitui-se em importantíssimo elemento num estudo ligado à temática ambiental, pois o mapa mais atualizado sobre uma determinada localidade auxiliará, dentre outros, a identificação e localização dos agentes responsáveis pelas condições ambientais da área, com o intuito de se propor um planejamento. Informação sobre o uso da terra pode ser usada para desenvolver soluções para a gestão de problemas relacionados a recursos naturais (LIRA, 2017) Geralmente onde não há planejamento do uso da terra adequado, ocorre degradação exacerbada da terra. A relação entre sociedade e natureza tem acarretado impactos ambientais, devido à necessidade de uma maior exploração dos recursos. 


\section{OS DESAFIOS DA GEOGRAFIA FÍSICA NA FRONTEIRA DO CONHECIMENTO \\ Instituto de Geociências - Unicamp \\ Campinas - SP \\ 28 de Junho à 02 de Julho de 2017}

Segundo Rosa (2003) a utilização de dados atualizados de uso e revestimento da terra é muito ampla, podendo-se citar como exemplo: inventário de recursos hídricos, controle de inundações, identificação de áreas com processos erosivos avançados, avaliação de impactos ambientais, formulação de políticas econômicas, etc.

As modificações ocorridas em certas localidades se repercutem em heranças deixada e resíduos das alterações, nesse contexto, o trabalho tem como objetivo avaliar a dinâmica vegetacional e do uso das terras na região do Parque Nacional Serra de Itabaiana desde antes da criação da área de reserva e posterior ao decreto de criação de 15 de junho de 2015 publicado no diário oficial da união edição número 114 de 16 de junho de 2005.

\section{LOCALIZAÇÃO DA ÁREA DE ESTUDO}

Localiza-se na região do Agreste de Itabaiana, coordenadas $10^{\circ} 44.916^{\prime}$ S e $37^{\circ} 20.435^{\prime} \mathrm{O}$, dista 45 quilômetros da cidade de Aracaju, acessado pela Br-235 e está inserido nos municípios de Areia Branca, Itabaiana, Itaporanga D'ajuda, Laranjeiras e Campo do Brito. O objetivo principal da Unidade de Conservação (UC) é proteger uma ilha remanescente de Mata Atlântica, e a fauna, flora e recursos hídricos e paisagísticos nela inseridos, bem como promover a pesquisa, educação ambiental e turismo ecológico. Sua área abrange 7.966 hectares e o perímetro $87,25 \mathrm{~km}$.

Está localizado em uma zona de transição entre a caatinga e a Mata Atlântica, de clima semiárido, com precipitação anual variando entre 1100 e 1300 mm em estações bem definidas, e umidade relativa média mensal de $84,6 \%$. Predomina um relevo ondulado e suave ondulado, constituído pelo "Domo de Itabaiana", representado pelas Serra de Itabaiana, Comprida e do Cajueiro, com altitudes variando entre 400 e 659 metros. A área é constituída por interflúvios tabulares e colinas, dissecada pela rede de drenagem.

É uma importante região de fornecimento de água para as comunidades do entorno e a capital do estado, contribuindo diretamente com $30 \%$ do abastecimento da cidade de Aracaju (Rio Poxim) que tem as suas nascentes na Serra.

\section{METODOLOGIA}

Para a realização deste trabalho foram adquiridas duas imagens de satélites TM LANDSAT-5, através do Instituto Nacional de Pesquisa Espacial (INPE), disponibilizadas gratuitamente no catálogo do site, respectivamente dos anos de 2013 e 2015

As imagens foram processadas no software de geoprocessamento ArcGis com a ferramenta Image Analysis e Image Classification, sendo possível realizar o tratamento das imagens e posteriormente o 
XVII Simpósio Brasileiro

de Geografia Fisica Aplicada

I Congresso Nacional

de Geografia Física

\section{OS DESAFIOS DA GEOGRAFIA FÍSICA NA FRONTEIRA DO CONHECIMENTO \\ Instituto de Geociências - Unicamp \\ Campinas - SP \\ 28 de Junho à 02 de Julho de 2017}

cálculo do Normalized Difference Vegetation Index (NDVI). As bandas foram empilhadas e a banda 4 substituída pelo NDVI e desse novo empilhamento a imagem gerada pode ser fatiada e classificada em categorias.

\section{RESULTADOS E DISCUSSÕES}

Os valores obtidos com o Índice correspondendo a -1 a 1, puderam ser relacionados a vegetação mais rala a mais densa, bem como área de nuvens (sendo destacada na cor vermelha) representando-as em diferentes tons de cinza. A partir da elaboração dos índices e posterior fatiamento e classificação, a imagem correspondente apenas a área do Parque chegou-se ao seguinte resultado: Pastagem, Vegetação Esparsa, Vegetação Densa, e assim, verificar as diferenças ocorridas na área no intervalo de um ano.

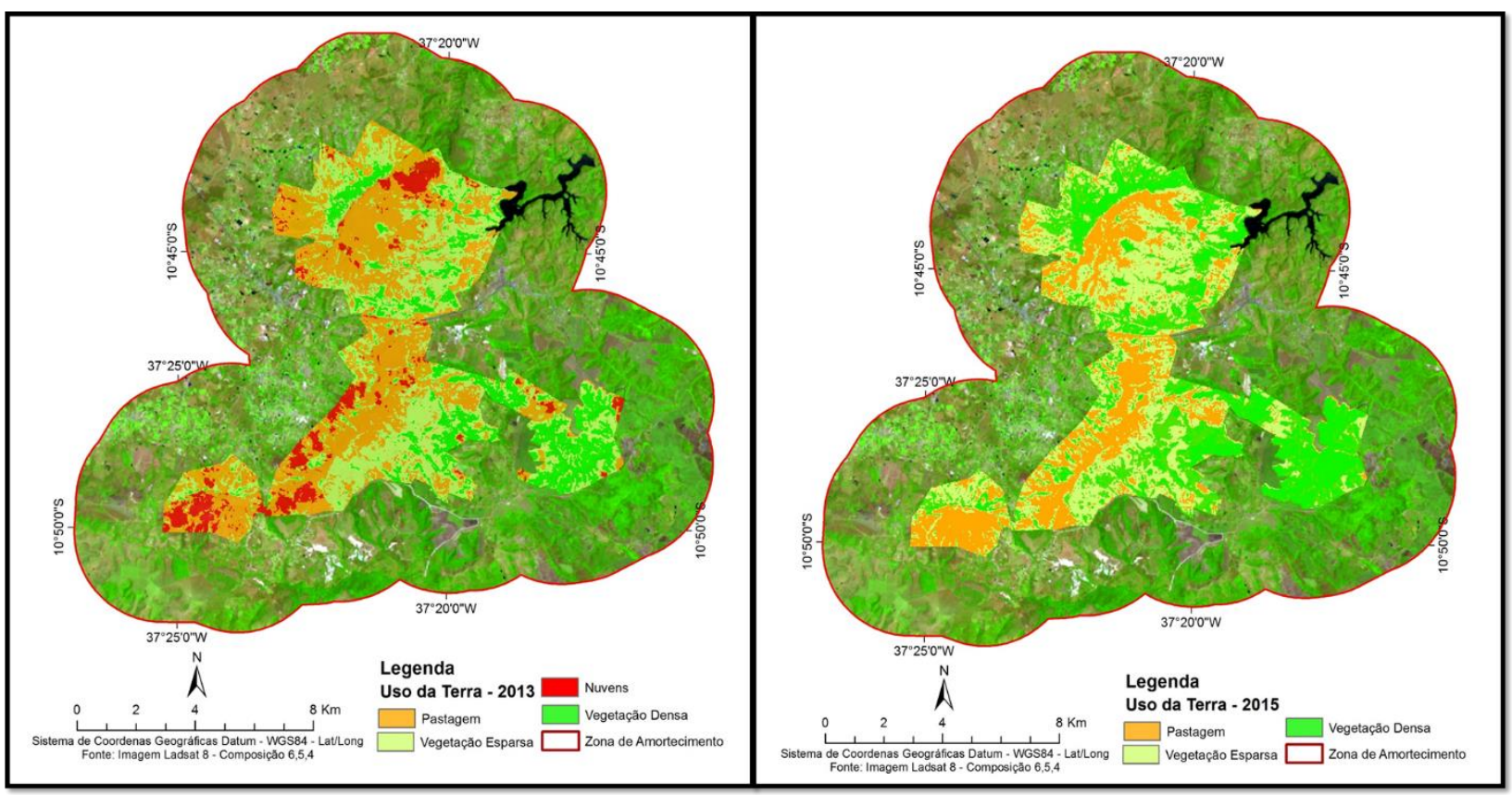

Figura 1 - Uso da Terra, 2013/2015. Elaboração dos autores.

$\mathrm{Na}$ análise dos dois mapas confeccionados perante aos estudos realizados, podemos identificar que neste período houve uma diminuição na zona de pastagem e aumento da vegetação densa. $\mathrm{O}$ que mostra a evolução na proteção dessa área que deve ser preservada e utilizada para pesquisas de cunho científico. Um dos fatores que contribui para a mudança na vegetação da área estudada, são ações antrópicas, existem várias ocorrências que conflitam com os objetivos da Unidade de Conservação (UC) e mesmo com a preservação ambiental já são conhecidas há bastante tempo. As atividades de acampamento por si só não representam um conflito com os objetivos de um Parque Nacional, entretanto as formas como são conduzidas podem se tornar uma ameaça, não há controle de acesso dos 
visitantes nem qualquer tipo de infraestrutura, embora sejam observadas clareiras para as barracas, onde também encontrados círculos de pedras usadas como fogões rústicos que usam lenha das redondezas.

\section{CONCLUSÕES/CONSIDERAÇÕES FINAIS}

Tem se observado a degradação ambiental é o fato de que ao entorno do Parque se encontram os municípios de Areia Branca e Itabaiana os quais estão em processo de desenvolvimento e crescimento em direção ao Parque, o que ocasiona invasões e ocupações irregulares no entorno da UC, bem como transforma a Unidade em uma ilha de conservação, aumentam também os conflitos com a fauna silvestre e a retirada ilegal de madeira. Existe extração vegetal dentro do PNSI, embora seja menos intensa do que antigamente, nela está incluída tanto à coleta de espécimes para ornamentação, quanto para uso medicinal e lenha, que ocorre por meio de corte seletivo ou desmatamento. Também pode ser observado a presença de olarias e pedreiras ao redor do Parque, alguns desses irregulares, com isso recursos naturais são retirados de forma irregular da zona de amortecimento do parque, sendo utilizadas para a construção de casas.

O Parque Nacional Serra de Itabaiana é o único Parque Nacional localizado no Estado de Sergipe, e inserido na região do Agreste/semiárida assim como outras áreas do semiárido nordestino, sofre intensa pressão antrópica, tanto pela retirada da vegetação para agricultura quanto pela pastagem e transformação em lenha.

O Sensoriamento Remoto hoje pode ser a melhor ferramenta para monitorar as áreas de reserva, uma vez que com sua utilização áreas que estão distantes podem ser monitoradas como também realizados estudos de mudanças desde o estado da vegetação, bem como o uso das terras dentro e no entorno dessas áreas.

\section{Bibliografia}

BRAZ. A. M. Et al. ANÁLISE DE ÍNDICES DE VEGETAÇ̃̃O NDVI E SAVI E ÍNDICE DE ÁREA FOLEAR (IAF) PARA A COMPARAÇÃO DA COBERTURA VEGETAL NA BACIA HIDROGRÁFICA DO CÓRREGO RIBEIRÃOZINHO, MUNICÍPIO DE SELVÍRIA - MS. Revista Percurso - NEMO Maringá, v. 7, n. 2 , p. $05-22,2015$.

LIRA. D. R. de. Et al. Mapeamento e Quantificação da Cobertura Vegetal do Agreste Central de Pernambuco Utilizando o NDVI. Revista Brasileira de Geografia Física 03 (2010) 157-16.

Plano de manejo Parque Nacional Serra de Itabaiana. Instituto Chico Mendes. Brasília, julho de 2016. 
CONSERVAÇÃO. III Simpósio Brasileiro de Ciências Geodésicas e Tecnologias da Geoinformação, Recife PE, 27-30 de julho de 2010 p. $001-006$.

SANTOS. F. de A. dos. USO DE IMAGENS LANDSAT PARA AVALIAÇÃO DA COBERTURA VEGETAL DO PARQUE NACIONAL DE SETE CIDADES (PI), NORDESTE, BRASIL. Cadernos Cajuína, V. 1, N. 3, 2016, p.24 - 35. 